\title{
Transition from the Prehistoric Age to the Historic Age: The Early Iron Age on the Korean Peninsula
}

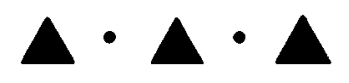

KISUNG YI

\section{INTRODUCTION}

THE APPEARANCE OF METAL OBJECTS IN THE PREHISTORIC PERIOD WAS OF GREAT SIGNIFICANCE. As iron implements became accepted as common tools used in everyday life and agricultural productivity increased, complex societies appeared and eventually developed into states. For this reason, archaeologists divide prehistoric times into periods based on the material attributes of new technologies. The periods that have been defined for most regions of the world are not much different from those used in the archaeology of Korea.

Korean archeologists define the Early Iron Age as the period from 300 B.C. to 100 B.C. during which cast ironware was distributed by the Yan (燕) dynasty. Although ironware is the most significant material marker of this cultural phase, the mass production of iron objects in general and ironware in particular was not fully realized during this period (KAS 2010:123). Situated between the Bronze Age and the ProtoThree Kingdoms period, the Early Iron Age is culturally significant because it serves as the transitional period between the Prehistoric and Historic eras. Despite this significance, the cultural characteristics of the Early Iron Age, its area of origin, and its relationship with earlier indigenous cultures have yet to be explained.

This article examines the concept of an "Early Iron Age" in Korea and the cultural characteristics that define it. It also reviews various issues and debates within studies on the Early Iron Age. For instance, in Korea the Early Iron Age is defined materially primarily by the presence of Jeomtodae (clay-striped) pottery and slender bronze daggers. Although it is generally accepted that ironware culture originated in the Early Iron Age, the Jeomtodae pottery culture and slender bronze dagger culture are not interpreted in the same way by all researchers. In addition, there is the important issue of the relative weight that different data sources (i.e., archaeological evidence, historical accounts) should be given. Historical accounts by foreign societies can be biased by cultural differences and the political agendas of the authors in the period in which they were written. For example, Chinese literature lists names of countries that Chinese authors claimed existed in some parts of the Korean Peninsula (e.g.,

Dr. Kisung Yi is a professor in the Department of Archaeology at Korea National University of Cultural Heritage. He received his Ph.D. in archaeology from Ritsumeikan University in Japan. His primary research interest is the comparative study of Korean Prehistory and Japanese Prehistory. 
Gojoseon 古朝鮮). Whether archaeologists recognize the existence of such countries and include them in currently established cultural period divisions in Korean archaeology is a very important issue, since there are differences between the divisions made by academic archaeologists and the historical divisions understood by the nonacademic public.

\section{WHY THE "EARLY IRON AGE” INSTEAD OF THE "IRON AGE”?}

The Early Iron Age is considered the most distinctive period in Korean archaeology because it precedes the emergence of state societies. Since the Early Iron Age is followed by the Proto-Three Kingdoms period, the term "Early Iron Age" represents neither an independent period (such as the Jomon and Yayoi periods in Japanese archaeology) nor the chronological division of classical archaeology. Some scholars, especially those who do not understand how archaeologists develop significant cultural phases or who do not work outside Korea, consider calling a period the Early Iron Age without it being followed by a Late Iron Age rather ambiguous.

In 1966, Won-Yong Kim was the first to suggest that the very significant period prior to state development should be called the Early Iron Age. How this period is defined has gone through various revisions since then. In the 1960s, Korean archaeologists were making an effort to overcome the Korean archaeology established by Japanese imperialists by creating an independent system of archaeological nomenclature. The archaeological periods were at that time divided into the Palaeolithic, Neolithic, Bronze Age, Early Iron Age, Gimhae culture, and Three States period (including Goguryeo, Baekje, and Silla).

The ironware culture of the Early Iron Age was considered by scholars to have been established during China's Warring States period. It eventually combined with ironproducing Bronze Age cultures in the north. Concurrently, what is known as "Gimhae culture" developed as cultural elements of China's Han dynasty were introduced into what is commonly referred to as the "Dolmen" society that had existed in South Korea since the Bronze Age (Kim 1966). Views about the use of the term "Gimhae culture" were debated until finally the ironware culture of the Early Iron Age was distinguished from the Proto-Three Kingdoms period in Won-Yong Kim's (1973) influential synthesis of Korean archaeology and Korea's first published introduction to archaeology. Won-Yong Kim labeled the period from 300 B.C. to 0 B.C. as the Early Iron Age. He included the ironware culture of the Early Iron Age with late Bronze culture, based on the assumption that the introduction of ironware into the Korean Peninsula barely distinguished this period from the well-developed Bronze Age culture.

Korean archaeologists later modified these periods into the following sequence: Old Stone Age (Palaeolithic), New Stone Age (Neolithic), Bronze Age, Early Iron Age, Proto-Three Kingdoms period, and Three States period. The term "ProtoThree Kingdoms" was an addition to the original Three States nomenclature and was intended to be used not only in the field of history but also in archaeology (Kim 1986:128).

After some scholars argued that distinctions between the Early Iron Age and the Proto-Three Kingdoms Period were ambiguous, the term "Early Iron Age," defined as the period from 300 B.C. to 0 B.C., became distinguished from the "Late Bronze Age" (Kim 1977). In later editions of his book, Won-Yong Kim defined the Early 
Iron Age by an emphasis on indigenous production of iron and expansion of bronze production: "Around $300 \mathrm{BC}$, local production of iron was developed, production of bronze objects was significantly increased and bronze ware technology was greatly advanced. However, the actual level of cultural attainment was a cultural stage where ironware was used" (Kim 1986:102; my translation).

Confusion about the term "Early Iron Age" and what period it represented stemmed from the fact that scholars from different disciplines did not share a unified perspective on the 600-year span from 300 B.C. to A.D. 300. Those 600 years lie between, and were a time of transition from, the Prehistoric Age (more specifically, the Bronze Age) and the Historic Age (more specifically, the Three States period). Furthermore, the absolute dates for the Early Iron Age were not based on archaeological material but rather on literary records. Specifying the year 300 B.C. as the starting point for this period is based on the historical fact that General Kai Qin (秦開) of the Yan dynasty invaded Gojoseon that year, instigating the spread of Yan dynasty culture. Similarly, 0 B.C. is considered in historical records (i.e., The Chronicles of the Three States) to mark the establishment of the Three Kingdoms (Goguryeo, Silla, and Baekje) in the late first century B.C. (Lee 2013:4). The question then becomes how to perceive a certain period from an archaeological perspective in conjunction with a historical perspective. From the archaeological perspective, the entire 600 years from 300 B.C. to A.D. 300 was the Iron Age. However, since it was also a period of transition from the Prehistoric Age to the Historic Age, it could be divided into two periods. From 300 B.C. to 0 B.C. was called the Proto-Three Kingdoms period to represent the phase preceding the development of ancient kingdoms from the historical perspective. Archaeologist Won-Yong Kim (1986) considered the cultural pre-phase of the Proto-Three Kingdoms period an early stage of ironware culture, hence the term "Early Iron Age."

Aside from whether to view it from the archaeological perspective or from the historical perspective, there has been much debate about whether or not to consider the 300 years after 300 B.C. part of the Bronze Age or consider it a culturally independent age. Only after many attempts to define it did Korean archaeologists finally accept the period division in the 1980s. Dispute continued about whether to consider the period from 300 B.C. to A.D. 300 (during which ancient kingdoms first appeared) as a single period of trajectory toward state development from the archaeological perspective, or to separate out the period from 300 B.C. to 0 B.C. as a distinct archaeological phase marking the end of prehistory. Even now deliberations continue about whether the term "Early Iron Age" is appropriate and whether it is possible to distinguish an Early Iron Age from the Proto-Three Kingdoms period.

One prominent argument in the 1990s was whether the entire period from 300 B.C. to A.D. 300 should be regarded as the Iron Age (Choi 1998) or as the Three Han States (Shin 1995). This reveals that the most important part of the terminology dispute concerns the historical significance of the era, rather than the terminology itself. Some archaeologists argued for use of the term "Iron Age" by asserting that the term "Proto-Three Kingdom period" focused too strongly on the historical perspective (Choi 2004). However, the even more historical term "Three Han States" is still used in discussing the Yeongnam area in southeastern Korea. According to Chinese literature, the Three Han States of Mahan (馬韓), Byeonhan (弁韓), and Jinhan (辰韓) were located in the southern Korean Peninsula. They are generally believed to have developed between 0 B.C. and A.D. 300. The term "Proto-Three Kingdoms" then makes chronological sense, as it suggests a period that comes before the establishment 
of three kingdoms, that is, the Three Han States. Replacing the archaeological term "Early Iron Age" with either of these historical terms would not make sense, however, because the historical terms are only applicable to the southern part of the Korean Peninsula. Some scholars insist that the three states or kingdoms terminology should not be used to describe the time period for the entire Korean Peninsula (Lee 2004).

Archaeologists have continued to use the terms "Early Iron Age" and "Proto-Three Kingdoms" despite these qualms. Those who advocate use of Early Iron Age point out that ironware was introduced to the Korean Peninsula from China in 300 B.C. From that date forward can be considered the Iron Age and, because ironware initially appeared only in the northwest and around the Geum River, that time can be classified as the Early Iron Age (Lee 2002). This argument demonstrates the archaeological perspective quite well, in much the same way as those conceptualizing the period as the Iron Age (Choi 2004).

The date marking the transition from the Early Iron Age to the Proto-Three Kingdoms period was not revised from 0 B.C. to 100 B.C. until the early 2000s. Ironware only began to be produced in earnest in southeastern Korea after the installation of the Four Commanderies of the Han (漢四郡), which is regarded as the real beginning of the Iron Age throughout Korea, along with the initiation of the Proto-Three Kingdoms period (Lee $2004: 89$ ).

The confusion caused by these terms stems from two causes. First, as already discussed, the confusion pertains to having two different perspectives, that is, either the archaeological perspective or the historical perspective, on the transition from the Prehistoric Age to the Historic Age. From the archaeological perspective, the entire 600 years from 300 B.C. to A.D. 300 should be regarded as the Iron Age, which could be divided into an early period of introduction of ironware in the north and a late period by which time full-scale ironware production was occurring. The historical perspective favors dividing periods according to the establishment of different polities, not material culture. The terms Early Iron Age and Proto-Three Kingdom period are an attempt to accommodate both archaeological and historical perspectives.

A second source of confusion is that the level of cultural introductions of ironware to the Korean Peninsula varied greatly by region, but took place within a short period of time. The Early Iron Age encapsulates a period of only 200 years (from 300-100 B.C.). This is such a short time that it cannot feasibly be considered a specific age commensurate with other Korean cultural periods. In addition, the ironware that acts as a criterion for defining the Early Iron Age and that can be dated to earlier than 100 B.C. has been discovered only in extremely limited areas. Since this and other cultural characteristics cannot be widely confirmed, some scholars are reluctant to designate a single term to represent the period for the entire Korean Peninsula.

Korean archaeologists are still uncertain whether the Early Iron Age can be considered an independent period (similar to the Jomon, Yayoi, and Kohun periods accepted in Japanese archaeology) or whether a classical method of dividing periods should be introduced. Although many Korean archaeologists now use the term "Early Iron Age," disputes about it continue.

\section{MATERIAL CULTURE IN THE EARLY IRON AGE}

The principle elements of material culture in the Early Iron Age are earthenware, bronzeware, and ironware. Given that the beginning of the Early Iron Age is defined 
by the introduction of ironware, ironware is naturally considered the most important technological marker for the period. Little early ironware has been excavated, however, so researchers recognize the usefulness of tracing cultural differences over space and time by examining pottery from this period. During the Early Iron Age, diverse forms of reddish-brown earthenware were produced following the Neolithic tradition. The most representative earthenware was Jeomtodae pottery, in addition to long-necked pottery, pottery bent outward at the rim, pedestaled pottery, and deep pots and jars. Jeomtodae pottery is generally defined as having a mouth surrounded by a round or triangular clay band. Temporal differences in the production of this distinctive pottery are seen in the specific shapes of the cross-sectional band (Fig. 1). Round cross-sectional bands were made earlier than triangular cross-sectional bands (Kim 1986).

Clay earthenware with round cross-sectional bands first appeared in central Korea, then spread to the Chungcheong, Jeolla, and Yeoungam provinces. Around 200 B.C., triangular Jeomtodae pottery appeared. There are two theories regarding its origin. Some insist that the triangular cross-sectional shape was created locally, while others argue that it was introduced from Liaoning (遼寧) in China or from northwestern regions of the Korean Peninsula. Archaeologists first discovered triangular crosssectional Jeomtodae pottery only in Yeoungam Province. Later finds of this type of pottery in various areas in the central Korean Peninsula necessitated developing new theories regarding its origin (see discussion in next section).

Earthenware featuring clay bands attached to the mouths of pots continued to appear in various periods from the Neolithic through the Bronze Age, but it is difficult to ascertain that the Jeomtodae pottery of the Early Iron Age is connected to the earthenware produced in previous periods on the Korean Peninsula (Park 2013). Round cross-sectional banded Jeomtodae pottery has been discovered in various areas in South Korea dating from the fifth to the second century B.C., while triangular cross-sectional Jeomtodae pottery has been dated to as late as the first century A.D. in Yeoungam Province. For this reason, while many accept that Jeomtodae pottery is the most representative artifact originating from the Early Iron Age, in reality Jeomtodae pottery continued from the Late Bronze Age to the Proto-Three Kingdoms Period. The earliest round cross-sectional banded Jeomtodae pottery made on the Korean Peninsula has mainly been discovered in centrally located sites, including Suseok-ri in Yangju, Gyoseong-ri in Boryeong, and Banje-ri in Anseong; triangular cross-sectional banded Jeomtodae pottery has been excavated in shell mounds and settlements in Neuk-do in Sacheon and Gungok-ri in Haenam in southeastern Korea (Fig. 2).

In addition to earthenware, bronzeware is another form of material culture representative of the Early Iron Age. The slender bronze dagger is cited as the most prominent type of bronzeware in Korea during this period. The slender bronze dagger is a bronze dagger with a straight blade with a dent in it and an attached separate handle. It is also known as the "Korean-style slender bronze dagger" to differentiate it from the lute-shaped bronze daggers of the Bronze Age and the slender bronze daggers found in Liaoning in China. Slender bronze daggers appeared in the fourth and third centuries B.C. Weapons such as bronze spears, tools such as axes and chisels, and household goods such as bronze mirrors and various other kinds of bronzeware dating to the same period have also been excavated in addition to slender bronze daggers. Representative relics were discovered in Namsong-ri in Asan and Goejeong- 

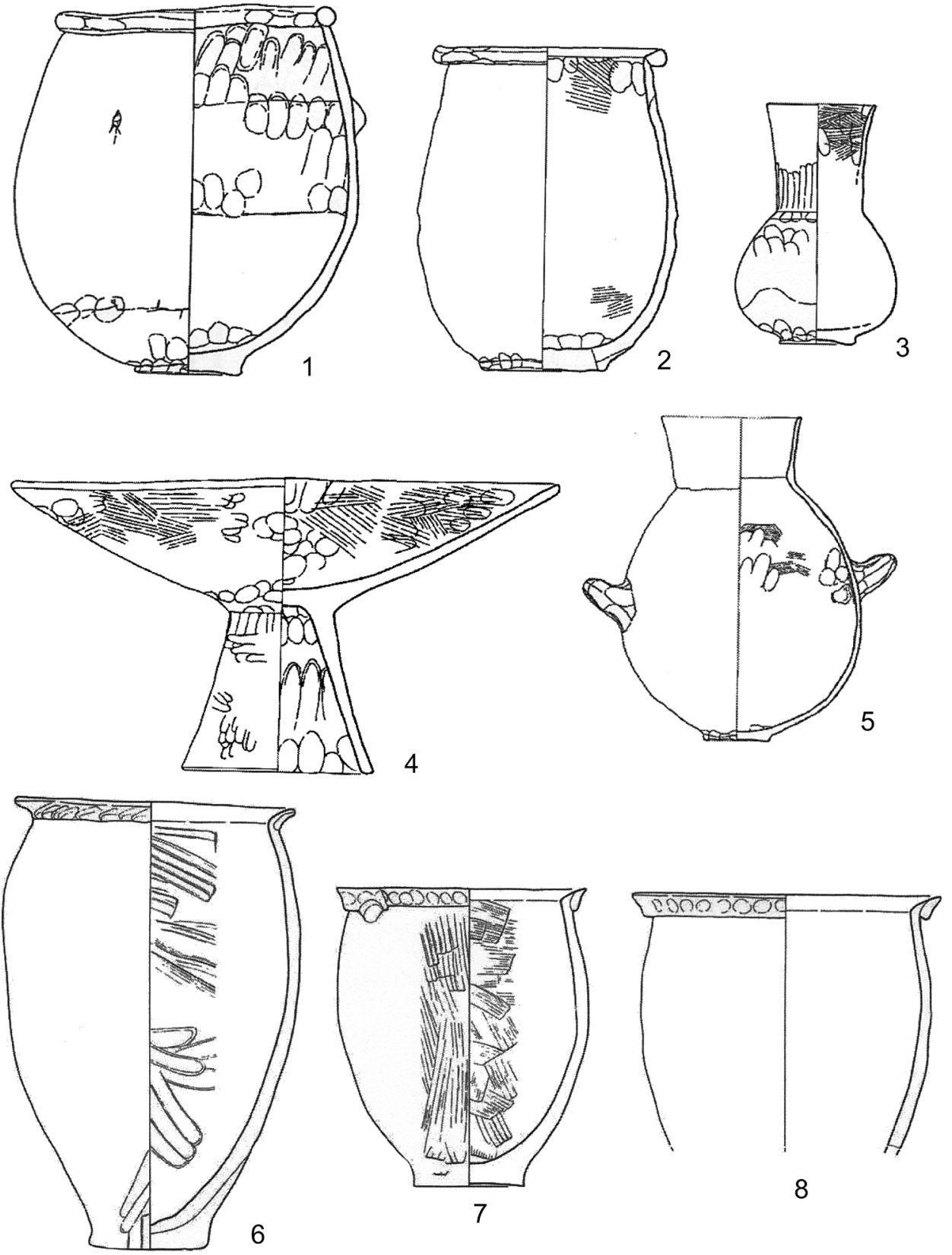

8

Fig. 1. Early Iron Age pottery. 1-2: Jeomtodae pottery; 3: black, burnished, long-necked pottery; 4: pedestaled pottery; 5: jar with handle; 6-8: deep pots. Sources: $1-5$ adapted from JCPI 2007; 6-8 adapted from SICP 2006 (drawings not to scale).

dong in Daejeon. In the third and second centuries B.C., bronze bells were added to the list of the various kinds of bronzeware in use (Lee 2013:6). Representative artifacts have been discovered in Chopo-ri in Hampyeong and Daegok-ri in Hwasun (Fig. 3). 


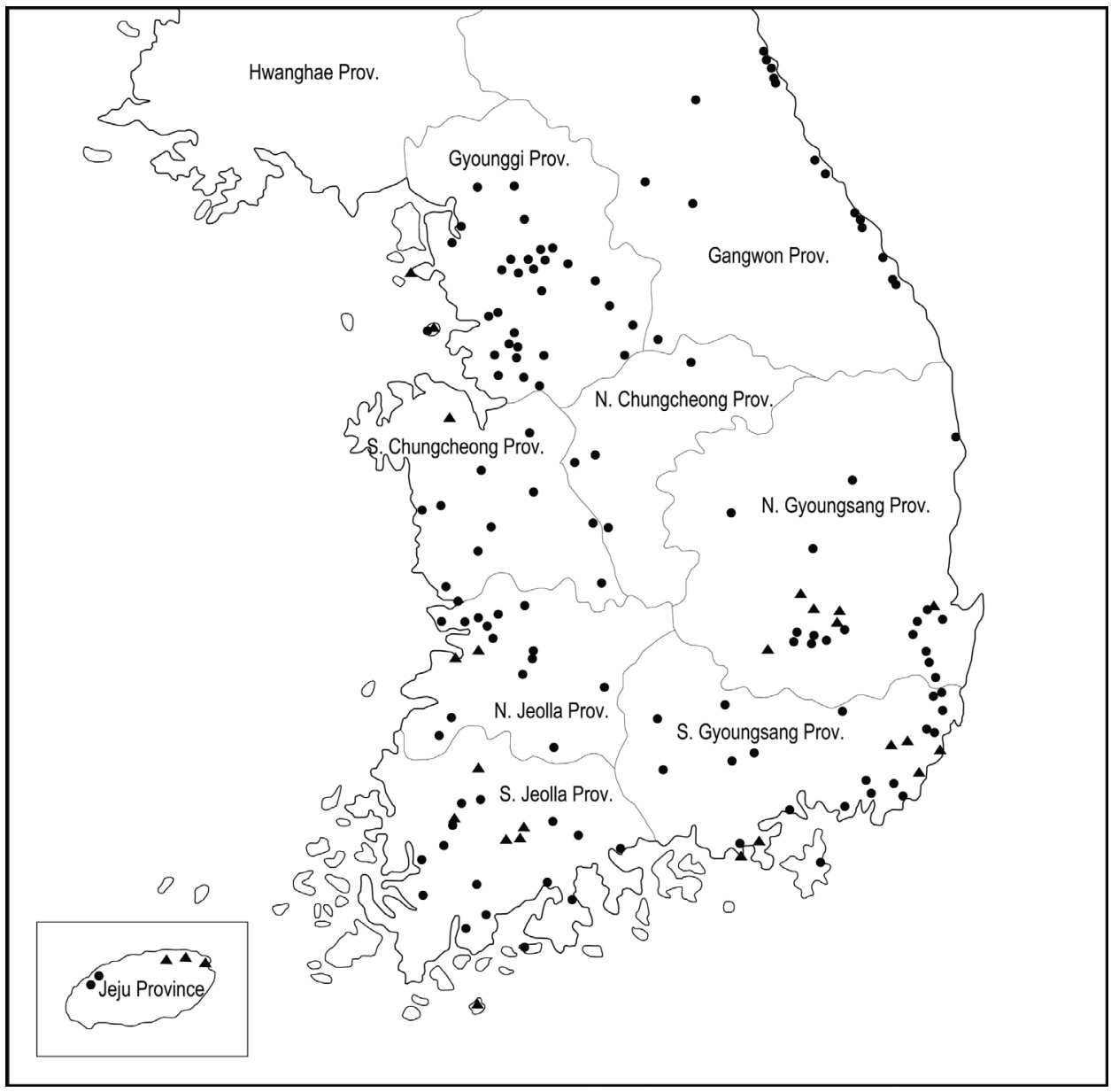

Fig. 2. Distribution of Jeomtodae pottery ( $\bullet$ round clay band $\boldsymbol{\Delta}$ triangular clay band). Source: modified from Lim 2009: 12 .

Changes in the form of bronzeware artifacts were likely associated with internal processes of development as well as interactions with foreign societies that led to the introduction of external forms of material culture. Bronze spears in the late stage are assumed to have originated from Liaoning, harkening the addition of a new foreignderived element of material culture. Another and almost certainly introduced kind of object was the advanced bronze mirror with a slim linear design and coarse lines. Despite these foreign introductions, bronzeware developed at earlier stages continued to be made. Earthenware excavated concurrently with bronzeware is the same as the round cross-sectional banded Jeomtodae pottery, indicating that existing bronzeware relics were mostly kept intact and added to other artifacts.

Distinct assemblages of bronzeware artifacts have been found in the southern Korean Peninsula. One type of assemblage found in Namsong-ri, originating from the fourth century B.C. to the third century B.C., is concentrated in Asan Bay and around Geum River (Fig. 4). Another assemblage of artifacts, originating from the third to the second century B.C., is concentrated in Chopo-ri, around the 


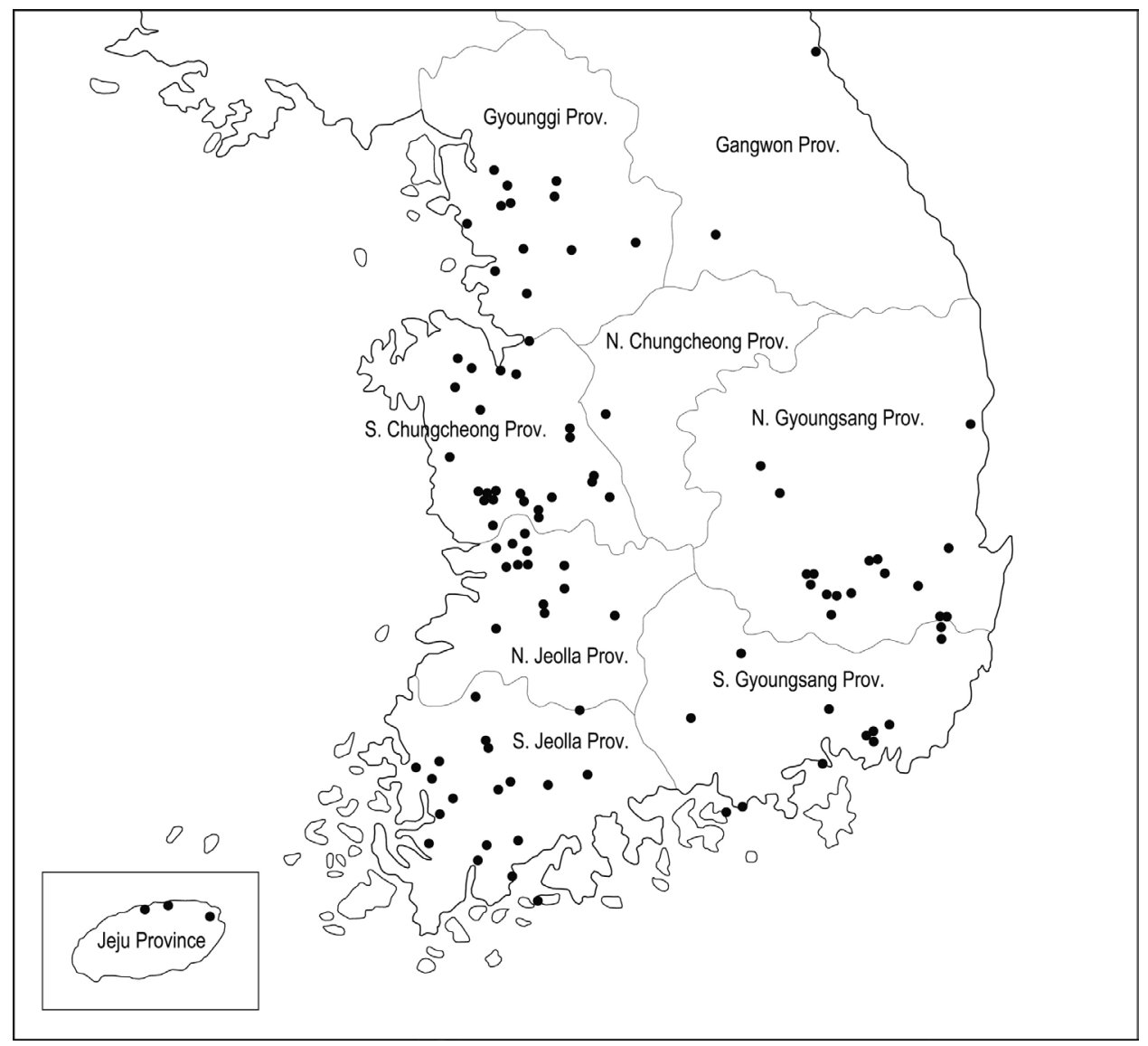

Fig. 3. Distribution of bronze implements. Source: modified from Jo 2004 : 26.

Yeongsan River in Honam Province, and in Yeoungam Province (Fig. 5). Various bronzeware casts excavated in Yeoungam in Jeollanam-do indicate that bronzeware was produced in the Korean Peninsula during this time period. The metallurgical casts suggest that the process involved combining two casts to create a single form; the casts were generally made of stone.

Compared with earthenware and bronzeware, ironware has been excavated only in small quantities on the Korean Peninsula. In terms of both quantity and range of kind, it appears to have been much less widely used compared to bronzeware. There is no tangible proof that ironware was produced on the Korean Peninsula during the period. Current evidence suggests that it was brought to the Korean Peninsula around the fourth century B.C. by the Yan dynasty. Ironware originating in the Early Iron Age has mostly been excavated north of the Cheongcheon River; it was not produced in earnest south of the river. South of Cheongcheon River, ironware has been excavated in small quantities from tombs in Hapsong-ri in Buyeo, Gal-dong in Wanju, and the Sinpung area. Many of these unearthed artifacts are axes and chisels; they have mostly been discovered in areas where bronzeware is also concentrated (Fig. 6). 


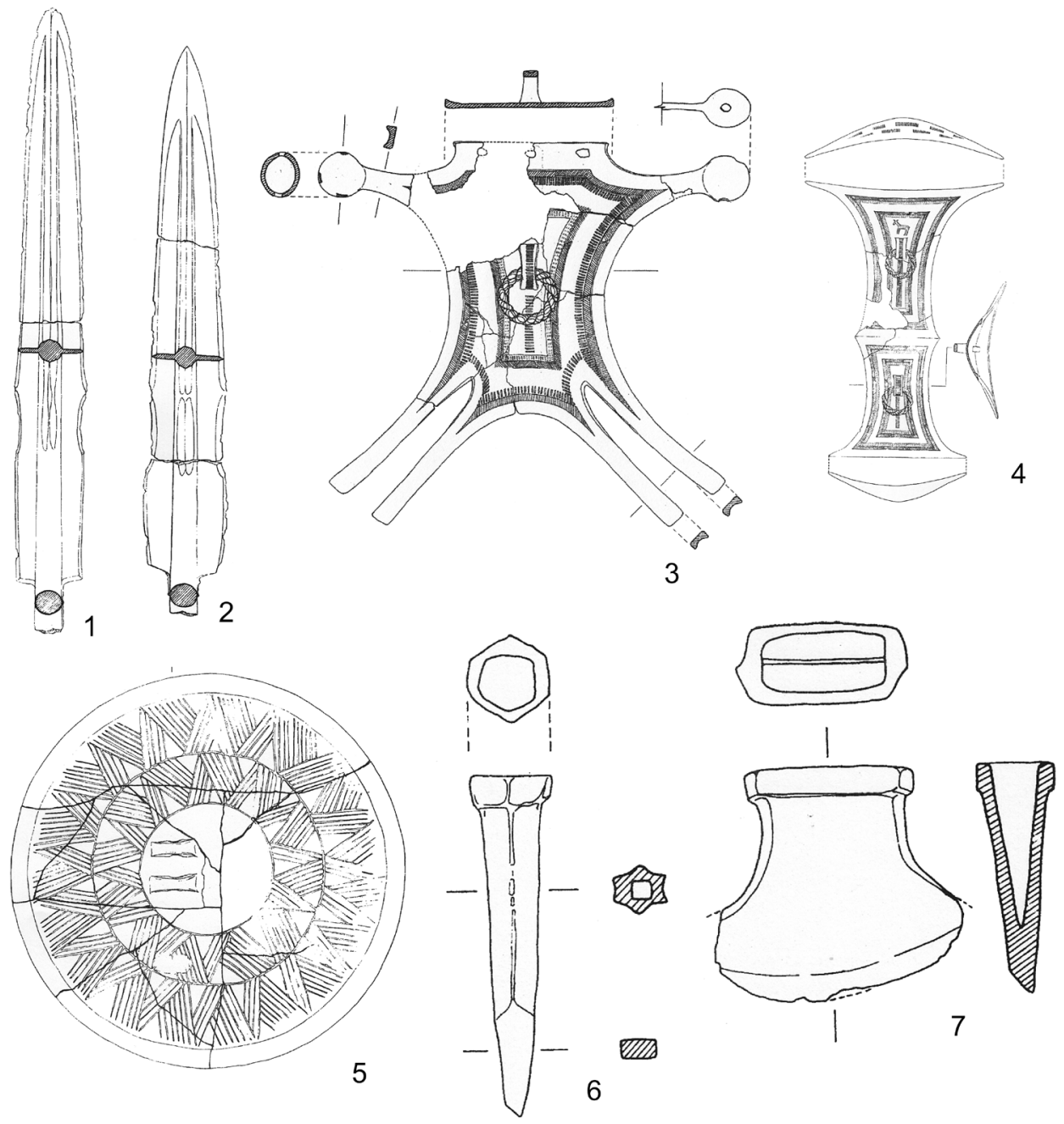

Fig. 4. Bronze implements from the Namsong-ri site. 1-2: slender bronze dagger; 3: shield-shaped bronze implement; 4: dagger hilt-shaped bronze implement; 5: bronze mirror; 6: bronze chisel; 7: bronze axe. Source: adapted from NMK 1977 (drawings not to scale).

Early Iron Age settlement sites contain rectangular-shaped pit dwellings, not much different in shape from those constructed in the Bronze Age, but somewhat smaller. Of these, house structures built on high ground (i.e., at the top of hills $100 \mathrm{~m}$ above sea level at the Gyoseong-ri site in Boryeong and the Banje-ri site in Anseong) stand out. Tens of pit dwelling sites were discovered at the Banje-ri site in Anseong. In addition, in some parts of Honam Province, Hoseo Province, and Jejudo Province, Jeomtodae pottery has been excavated from Songguk-ri-type dwelling sites originating from the Bronze Age, demonstrating the transition from the Bronze Age to the Early Iron Age.

Enclosed ditches have been discovered in some hillside settlement sites. These ditches are believed to be related to ancestral rites. The most representative type of 

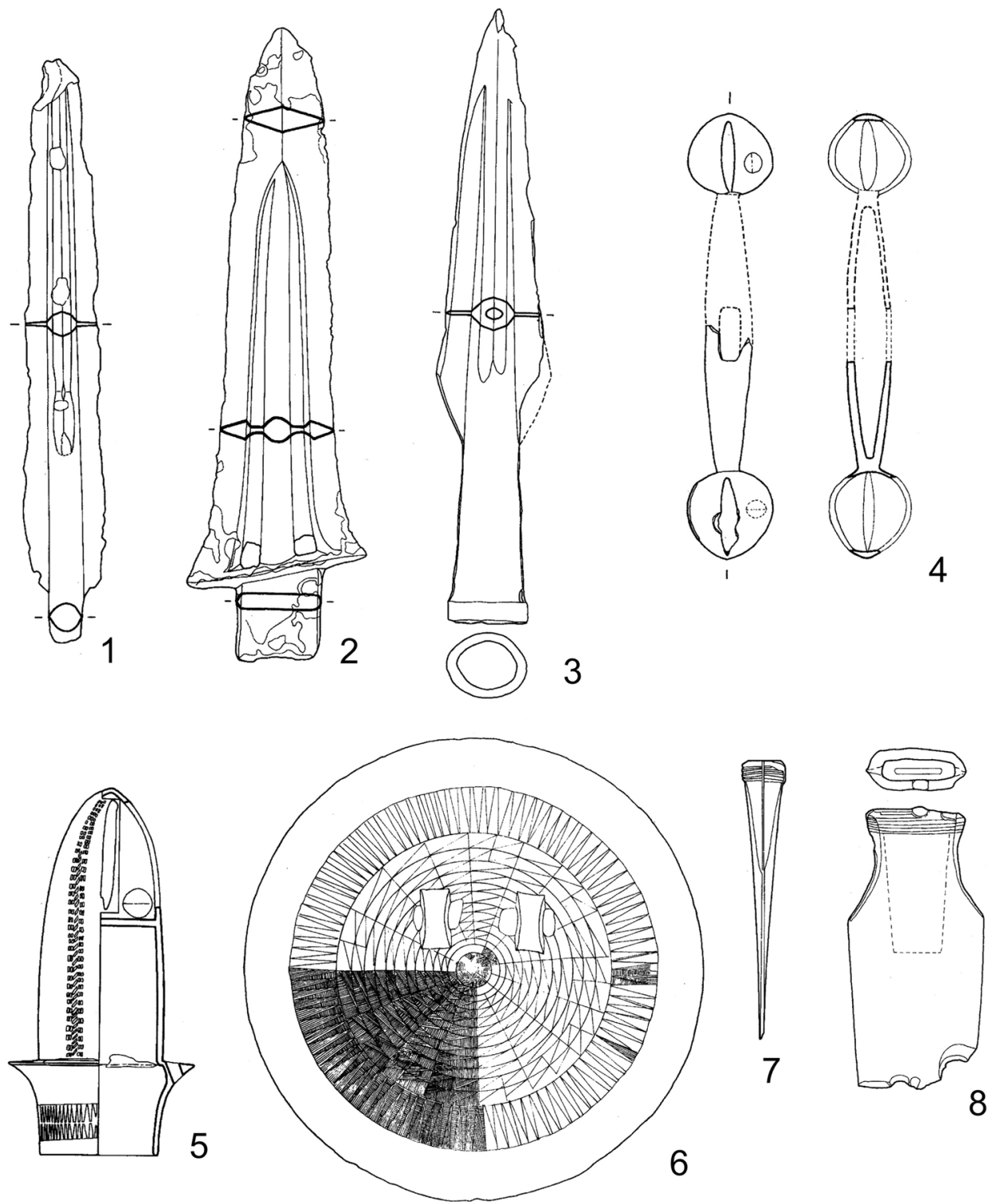

Fig. 5. Bronze implements from the Chopo-ri site. 1: slender bronze dagger; 2: bronze halberd; 3: bronze spearhead; 4: bronze double-head bell; 5: bronze pole-top bell; 6: bronze mirror; 7: bronze engraver; 8: bronze axe. Source: adapted from GNM 1988 (drawings not to scale).

Early Iron Age tomb is the wooden coffin tomb. This type of tomb appeared on the Korean Peninsula for the first time during the Early Iron Age and continued to be used until the Proto-Three Kingdoms period. Numerous wooden coffin tombs have been discovered in Gal-dong in Wanju and the Sinpung area; Jeomtodae pottery was excavated along with ironware in 70 or more wooden coffin tombs in the Sinpung area. However, bronzeware and ironware artifacts were not buried in Early Iron Age wooden coffin tombs in Seoul or Gyeonggi Province; only one or two pieces of 


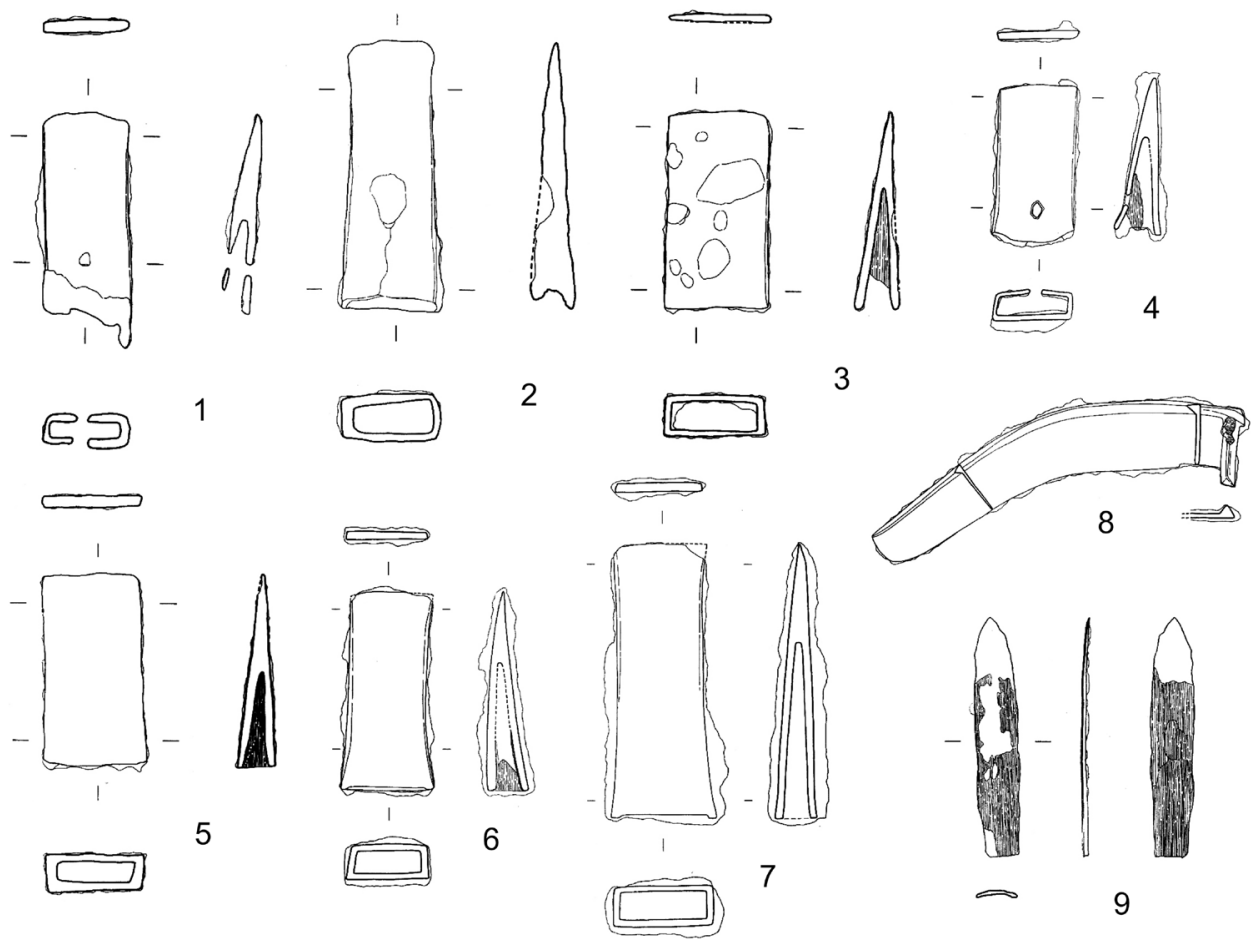

Fig. 6. Iron tools from the Galdong site. 1-7: cast iron axes; 8: iron sickle; 9: iron engraver. Source: 1-5 and 9 adapted from HCPRC 2009; 6-8 adapted from HCPRC 2005 (drawings not to scale).

earthenware were buried in most cases, representing a different burial pattern in those places (KAS 2010:135).

\section{ORIGIN OF EARLY IRON AGE MATERIAL CULTURE}

As already described, the material culture of the Early Iron Age is represented by certain types of earthenware, ironware, and bronzeware. These elements of material culture do not all appear on the Korean Peninsula at the same time or originate from the same area. It is generally believed that Jeomtodae pottery and bronzeware were introduced to the Korean Peninsula in tandem from the same area of origin, but that the source area and timing of the introduction of ironware were different. Given incongruent origins and dates of appearance on the Korean Peninsula, which of these artifact suites most accurately represents definable cultural characteristics of the Early Iron Age? To answer this question, it is first necessary to understand the different courses by which each of these elements of material culture were introduced to the region.

\section{Origin and Dissemination of Jeomtodae Pottery}

Studies seeking to determine the origin of Jeomtodae pottery, one of the most representative artifacts of the Early Iron Age, were initiated in the 1980s. These early studies 
considered the Han River course to be the area of origin of Jeomtodae pottery (Han 1981). This belief was based on the assumption that cultures northeast and northwest of the Korean Peninsula overlapped with the Han River course in the Bronze Age before spreading to the southern Korean Peninsula. Today few archaeologists accept the Han River system as the area of origin of Jeomtodae pottery, but it is significant that archaeologists have so fervently sought the origin of Jeomtodae pottery in this particular northern region.

In the 1990s, there was substantial research impetus to resolve this significant issue of the source of Jeomtodae pottery and hence the origin of Early Iron Age societies. Some scholars continued to insist that it originated from on the banks of the Han River, but argued that it developed during the Early Iron Age rather than earlier in the Bronze Age (Park 1993a). However, after noting that both Jeomtodae pottery and long-necked burnished black pottery were excavated in Liaodong, where the Chengchia-wa-tzu (鄭家窪子) site in Shenyang was discovered, researchers quickly changed their opinion and considered Liaoning to be the area of origin of Jeomtodae pottery (Park 1993b). At the end of the fourth century and in the early third century B.C., around the time General Kai Qin of the Yan dynasty led armed conflicts against Gojoseon during a period of civil war, residents of Liaoning are believed to have migrated into the Korean Peninsula (Kim 2001; Park 1993b; Yi 1994). Since the 1990s, many researchers have confirmed the presence of artifacts related to Jeomtodae pottery in Liaoning; it is now generally accepted that Jeomtodae pottery culture on the Korean Peninsula is related to the Shenyang area in Liaodong (Park 2013:31) (Fig. 7).

Although many archaeologists agree that Liaodong is the ultimate area of origin of Jeomtodae pottery, their opinions about the path of dissemination of this cultural matrix differ. The largest obstacle in determining the route of cultural interaction is that the distribution of Jeomtodae pottery is centered in the southern Korean Peninsula and it has hardly been documented in the northern Korean Peninsula. For this reason, it is commonly inferred that the pottery was spread by sea along the west coast, although archaeologists have conflicting opinions about the exact route this largely maritime-based process of diffusion could have followed. Some assert that the pottery spread from Liaozhong to mid-western regions by sea before it was disseminated from the river course of the Han River to various areas of the Korean Peninsula (Park 2013). Others insist that there was another path of dispersal to inland regions in addition to the sea route. It is believed that if Jeomtodae pottery spread to the northwest regions and was then disseminated into the mid-western regions by sea, other routes connected to Wonsan Bay, the eastern coast of Korea, and Yeoungam Province would have been used in addition to the sea routes (Park 2004). Doublerimmed pottery and grooved stone axes excavated in Namgyeong Dwelling Site No. 3 in Pyongyang are cited as evidence supporting the latter possibility, since this pottery is similar in shape to Jeomtodae pottery recovered at Goejeong-dong site in Daejeon (Park 1993b). The Jeomtodae pottery culture in Liaoning does not feature grooved stone axes, whereas the Jeomtodae pottery culture on the Korean Peninsula does, in addition to other stone tools. If the Jeomtodae pottery culture did originate in Liaoning, the people carrying this material culture into the Korean Peninsula or people adopting this pottery style shortly afterward must have come into contact with other groups using grooved stone axes on the Korean Peninsula. Some archaeologists also cite downstream areas of the Amnok River, the banks of the Cheongcheon River, and Wonsan Bay as possible inland paths of distribution (Park 2003). 


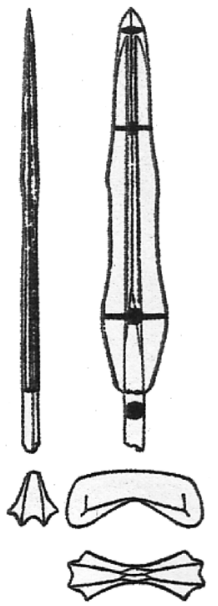

1

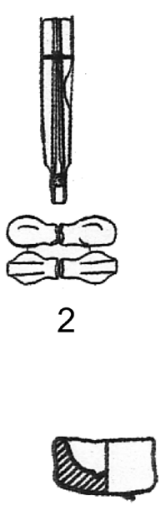

3

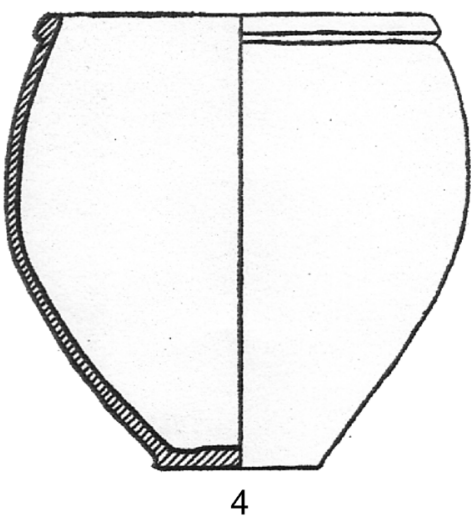

4

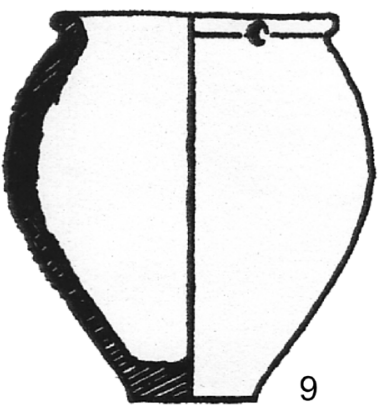

9

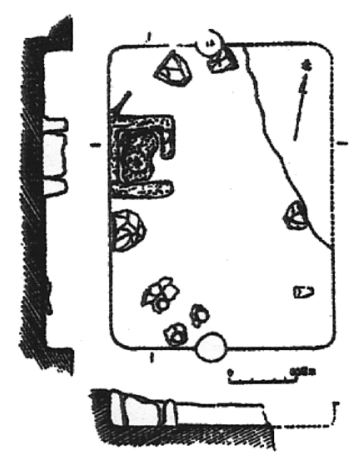

10

Fig. 7. Artifacts from Cheng-chia-wa-tzu site (1-5) and Gongzhutun site (6-9), Liaodong Province, China. 1-2: bronze dagger; 3: pot; 4, 7-9: Jeomtodae pottery; 5-6: black, burnished, long-necked pottery; 10: pit dwelling from Gongzhutun site. Source: modified from Park 2004:42 (drawings not to scale).

As for the double-rimmed pottery excavated from the Namgyeong site, the typical top-type was discovered in dwelling sites related to Dwelling Site No. 3, where Bronze Age earthenware and stone tools such as knives were also excavated (Fig. 8). Double-rimmed pottery is therefore considered by some archaeologists to belong to the Bronze Age. However, other archaeologists have insisted that, other than the Jeomtodae pottery found at Namgyeong Dwelling Site No. 3, no such pottery has been excavated in areas downstream of the Amnok River or Wonsan Bay (Park 2013:32). In short, while studies do seem to indicate that the Jeomtodae pottery culture originated in Liaoning, there continues to be dispute about how it was disseminated to the southern Korean Peninsula. 

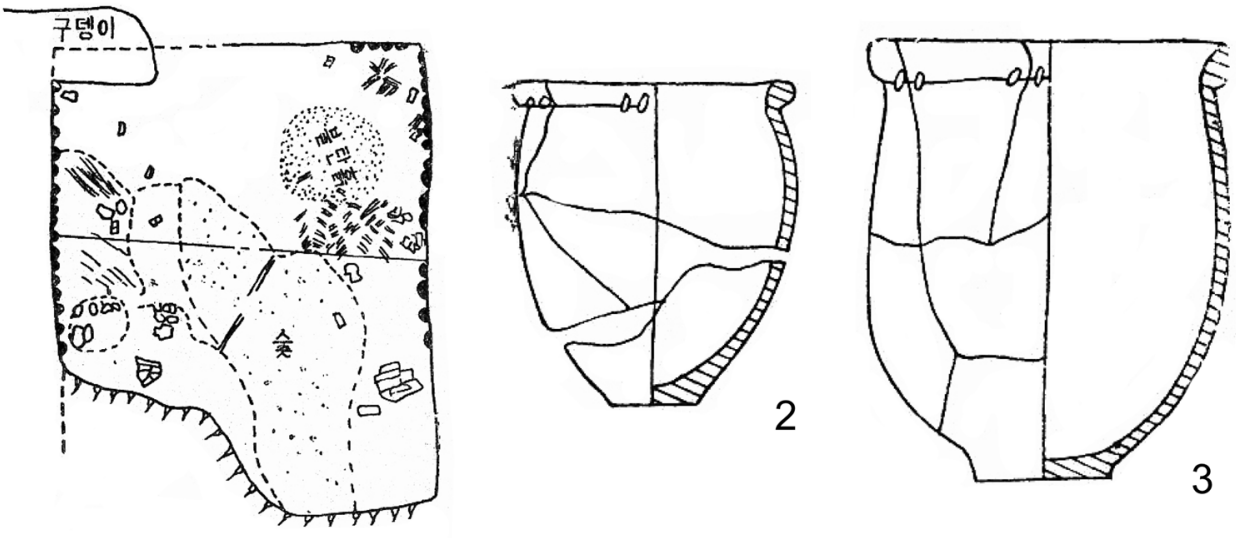

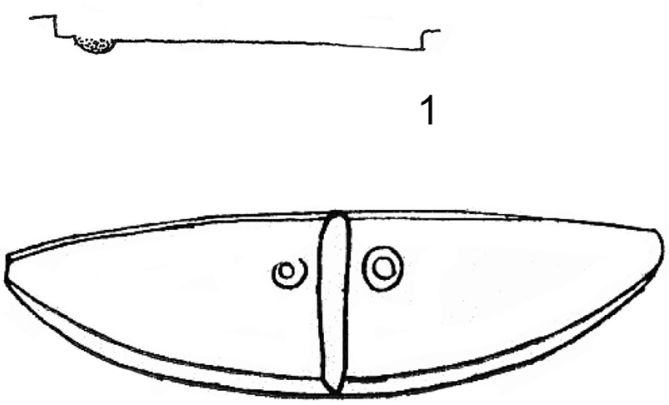

4

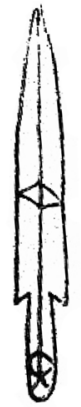

5

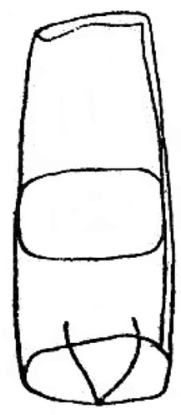

6

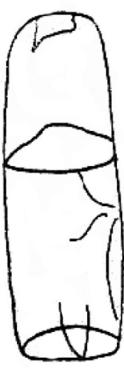

7

Fig. 8. Pottery and stone tools from Pit Dwelling No. 3, Namgyeong site. 2-3: double-rim pottery; 4: stone knife; 5: polished stone arrowhead; 6-7: polished stone axes. Source: adapted from Kim 1984 (drawings not to scale).

\section{Origin and Dissemination of Bronzeware}

As previously noted, bronzeware originating from the Early Iron Age is divided into two phases according to the composition of the artifact assemblages. The earlier bronze assemblages dating to the fourth and third centuries B.C. consist of weapons such as slender bronze daggers, tools, bronze mirrors, and diverse bronzeware. Assemblages from the later phase include tools and bronze mirrors (both unchanged since the earlier phase) and bronze bells added to weapons (instead of the bronze spears and diverse bronzeware of the previous phase) around the second century B.C.

Slender bronze daggers, the most representative bronzeware, developed from luteshaped bronze daggers that were distributed from the northeast area of China to the southern Korean Peninsula. Possible paths of dissemination are divided amongst the following three regions: Liaodong, Liaoxi, and the southern Korean Peninsula. However, the lute-shaped bronze dagger culture and slender bronze dagger culture of the Korean Peninsula do not appear to have been directly related to each other in terms of their association with types of tombs, shapes of dwelling houses, size range of bronze daggers, or methods of polishing metal. It is therefore difficult to assert that the slender bronze dagger culture developed from the lute-shaped bronze dagger cul- 
ture within the Korean Peninsula. Rather, the slender bronze dagger culture appears to be closely related to the Shenyang area in the northeastern provinces of China because the two areas present similar dwelling sites, wooden coffin tombs, Jeomtodaetype pottery, long-necked black pottery, bronze mirrors, and diverse bronzeware (Jo $2004: 162$ ).

For this reason, researchers claimed that the slender bronze dagger culture was paired with the Jeomtodae pottery culture to be eventually disseminated to the Korean Peninsula. However, there are still disputes over the dissemination path of the bronzeware. It seems most likely that sea routes were taken. Distribution by land is unlikely because no artifacts preceding the slender bronze dagger culture have been found in the region between Shenyang and the mid-western Korean Peninsula (Jo 2004 : 165). The slender bronze dagger culture must have come directly from the mid-western region of the Korean Peninsula before spreading to other regions on the peninsula. A similar conclusion can be drawn from the distribution of Jeomtodae pottery.

Material culture seems to have been introduced to the Korean Peninsula from northeast China not just once, but continually over time. Bronze spears introduced to the Korean Peninsula in the second phase of the Early Iron Age were highly likely to have been modeled after those made during the Qin (秦) dynasty in China. This indicates that the culture of the Qin dynasty was accommodated rather than rejected in Shenyang and that an independent slender bronze dagger culture could have been established on the Korean Peninsula (Jo 2004: 169).

\section{Origin and Dissemination of Ironware}

As mentioned earlier, the Early Iron Age was given its name based on the production and use of ironware during the period. However, the Early Iron Age developed slightly differently on the Korean Peninsula compared to farther north. Ironware dating to the first century B.C. has been excavated only in a very limited number of areas on the peninsula. North of the Cheongcheon River in North Korea, the only ironware excavated (known as the Sejukri-Lianhuabao assemblage) originated from China's Warring States period in the third and second centuries B.C. Ironware relics dating to the second century B.C. have been found in northwestern areas south of the Cheongcheon River, including along the riverbanks of the Geum River and around Weonsan Bay (Lee 2002:37). Ironware dating from the third century B.C. has also been excavated along the riverbanks of the Geum River, but ironware made prior to the second century B.C. has not been discovered in the Han River basin or Yeoungam Province, which were centers of previous cultures. Therefore, the Geum River discoveries are considered unique in South Korea (Lee 2002:43).

Since ironware molds were discovered in the northwestern provinces of the Korean Peninsula, ironware is believed to have been made within the region, but there is no record of such findings south of the Cheongcheon River. Whatever the place of origin, ironware culture was introduced to the Korean Peninsula around the third to second centuries B.C., which is when the Yan dynasty entered areas north of the Cheongcheon River. Prior to the installation of the Nakrang (樂浪) commandery in 108 B.C., there was no trace of the ironware culture except near the Geum River south of the Cheongcheon River. These facts suggest that ironware culture did not play a significant role on the Korean Peninsula in the Early Iron Age. 
Jeomtodae pottery was introduced to southern regions of the Korean Peninsula during the fifth century B.c., but ironware was introduced much later. Jeomtodae pottery was much more pervasive than ironware. It has been discovered throughout the southern Korean Peninsula, whereas ironware is found only in very limited areas. These differences indicate that the times and paths of dissemination were very different for these two material cultures.

\section{DISCUSSION}

Within the study of the Early Iron Age, there continue to be a number of academic disputes regarding what the term "Early Iron Age" represents as far as distinct cultural developments and the specific origins of the material culture representative of this cultural phase. Numerous theories have been advanced on each of these issues. The following discussion outlines the various hypotheses put forth by scholars.

\section{Timing of the Introduction of Jeomtodae Pottery and Bronzeware}

As noted above, both Jeomtodae pottery and bronzeware represent the most prominent forms of Early Iron Age material culture and both were distributed from Liaoning in China to the Korean Peninsula. The absolute age of this pottery and bronzeware has generally been determined from historical literature instead of by dating archaeological material. According to an ancient Chinese literary work entitled Shiji (史記), General Kai Qin of the Yan dynasty invaded Gojoseon and residents from Liaoning migrated to the Korean Peninsula between the end of the fourth century and the early third century B.C. (Park 2003). This historical evidence does not suggest that these forms of material culture (i.e., Jeomtodae pottery and bronzeware) were acquired through long-distance exchange networks between societies in Liaoning and Korea. It instead supports the theory that these new elements of material culture were brought by a foreign population migrating to the Korean Peninsula after having lost an armed conflict in the north. This is regarded as a significant migration and transfer of material culture because, in addition to Jeomtodae pottery, bronzeware has been documented at archaeological sites in both Liaoning and Korea. The Gongzhutun (公主屯) site in Shenyang, China is located on high ground and contains small, square, walled dwellings surrounded by open fields. These dwellings are very similar in form to the settlement sites containing Jeomtodae pottery on the Korean Peninsula (Park 2003: 62). The fact that not only artifact assemblages but also the shape and structure of the dwellings are similar is cited as strong evidence that groups of people who used these specific artifact assemblages collectively migrated to the Korean Peninsula (Park 2003).

There is no question that material culture on the Korean Peninsula from the Neolithic to the Bronze Age was influenced by that of northeastern China in various ways and it is certainly possible that these cultural elements were disseminated through migration. Researchers have usually suggested that climate change was the main reason for presumed migrations until the Bronze Age, but large-scale migration in the Early Iron Age could well have resulted from regional political conflict. New theories that political factors rather than ecological factors precipitated population movements have opened up considerably more varied interpretations than were previously in circulation among scholars. 
The migration-focused explanation depends on Jeomtodae pottery and bronzeware having disseminated into the Korean Peninsula at the same time, with ironware introduced much later. Based on new archaeological finds and a reassessment of the time span of Jeomtodae pottery, some archaeologists have recently suggested that Jeomtodae pottery was disseminated earlier than bronzeware. According to the traditional chronological interpretation, Jeomtodae pottery and bronzeware were spread into the Korean Peninsula around 300 B.C., but some scholars believe that Jeomtodae pottery was actually disseminated into the Korean Peninsula around 500 B.C. This is because some Jeomtodae pottery has been excavated in the same stratigraphic context as earthenware that originated from the Bronze Age (Lee 2011).

This new interpretation raises various issues. If Jeomtodae pottery arrived in the Korean Peninsula prior to the appearance of bronzeware, was it disseminated via a significant migration of outsiders into the region or did it diffuse through sporadic cultural trade contact? To date, no research has confirmed the presence of Jeomtodae pottery in the northern part of the Korean Peninsula, so collective migration by sea has been considered the only viable means of dissemination. However, it is difficult to find a particular reason for such collective migration around 500 B.C. Even more problematic is that Jeomtodae pottery cannot be considered representative of the Early Iron Age if it appeared on the Korean Peninsula in the Bronze Age.

\section{Relationship between Jeomtodae Pottery Culture and Indigenous Songguk-ri Culture}

Whether the Jeomtodae pottery culture appeared around 500 B.C. or jointly emerged with the bronzeware culture around 300 B.C., uncertainty remains concerning its relationship with the earlier indigenous bronzeware culture known as Songguk-ri. Bronze Age Songguk-ri culture was an advanced society that included large-scale settlements, stone coffin tombs, and rice farming. Those who migrated from Liaoning and brought Jeomtodae pottery to the Korean Peninsula were destined to come into conflict with these indigenous people living in large-scale, technologically advanced settlements. Archaeological evidence that indigenous societies came into contact with an external culture includes the presence of dolmens and Jeomtodae pottery excavated from Songguk-ri-type dwelling sites (Fig. 9). Slender bronze daggers, bronze axes, and Jeomtodae pottery have been excavated in dolmens, indicating that dolmens continued to exist beyond the Bronze Age into the Early Iron Age.

Jeomtodae pottery has occasionally been excavated from Songguk-ri dwelling sites in the mid-western Korean Peninsula. Circular Jeomtodae pottery has been excavated from Late Bronze Age dwelling sites in Youngdong Province. Given the forms of the dwellings and the nature of the excavated artifacts, these sites almost certainly belong to the Bronze Age. It seems appropriate to infer that indigenous people with a bronzeware culture came into contact with outsiders carrying elements of the Jeomtodae pottery culture. The indigenous people are regarded as the principal agent for transferring the circular Jeomtodae pottery into their cultural assemblage, to be included in their Bronze Age suite of technologies. Jeomtodae pottery would therefore be classified as Late Bronze Age pottery.

Despite their advanced technology, the Songguk-ri culture represented at large settlements became extinct in the Early Iron Age. It is still uncertain how or why all of the large settlements disappeared so suddenly. Determining factors in their abrupt 


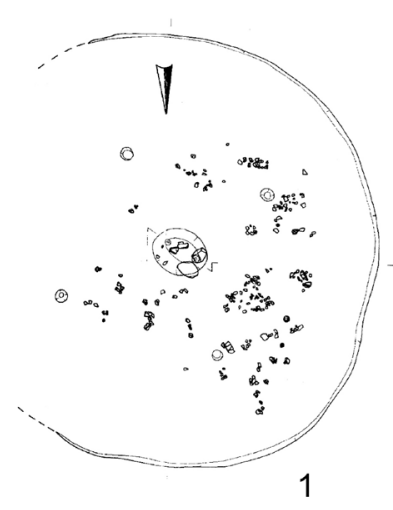

1

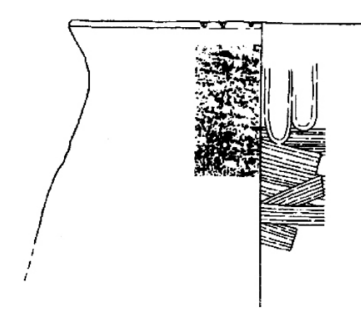

2
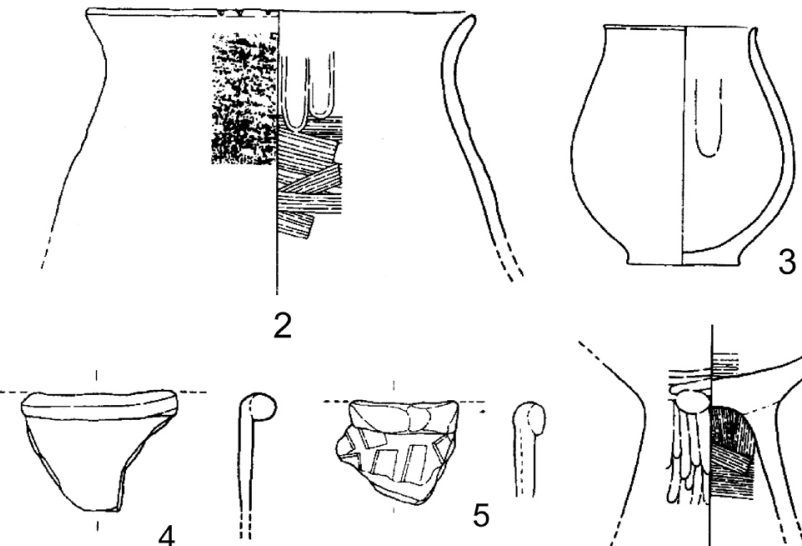
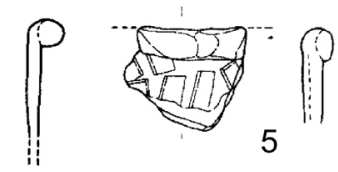

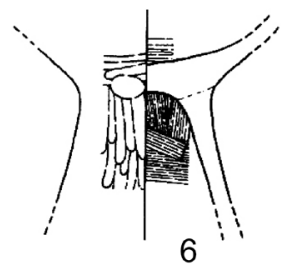

Fig. 9. Pottery from Songguk-ri-type pit dwelling KC-079, Gwanchangri site. 2: Songguk-ri type pottery; 3: red burnished pottery; 4-5: Jeomtodae pottery; 6: pedestaled pottery. Source: adapted from KIAE 2001 (drawings not to scale).

disappearance requires further research. As the large dwelling sites became extinct, small ones assumed the central role in regional settlement organization. These Early Iron Age dwelling sites tended to be located on hills (some up to $100 \mathrm{~m}$ above sea level) and were maintained for only short periods of time. Some archaeologists characterize these elevated settlements as defensive dwelling sites built during periods of conflict between outsiders and indigenous groups. Whatever the reason for the change in dwelling type, it is difficult to argue that the peoples of the Early Iron Age were more advanced than those of the Bronze Age in terms of their degree of social integration (Song 2013).

\section{Geographical Range of Early Iron Age Cultures}

When studying the Early Iron Age, it is important to determine the appropriate geographical region for examining settlement patterns and cultural interactions and trade, and map the geographic reach of certain archaeological phenomena that define regional cultures. Current national boundaries are irrelevant to studying the movements of people and the sharing of cultural elements in the past. Since it is difficult to confirm the current state of archaeological research conducted in North Korea, research on the Korean New Stone Age and Bronze Age has customarily been confined to southern areas of the Korean Peninsula (present-day South Korea). The same is true for studies of the Early Iron Age.

No epoch-marking incidents occurred during the 200 years of the Early Iron Age. For this reason, it is not appropriate to concentrate research on changes in southern regions of the Korean Peninsula. Researchers have no choice but to focus on areas of origin of likely imported materials that were prominent during the period. However, ironware (and bronzeware) has been excavated only in very limited areas on the Korean Peninsula. Jeomtodae pottery has only been excavated from the southern Korean Peninsula. For this reason, if ironware is valued as a cultural indicator of the Early Iron Age, it becomes necessary to deal with distinct archaeologically recorded cultures over a wide area, but centering on Liaoning (the suspected origin). In this case, the south- 
ern regions of the Korean Peninsula would be dealt with as possible "receptor populations" of certain elements of Early Iron Age culture in an area surrounding the core of Early Iron Age developments. However, if examining Jeomtodae pottery and its function in the southern regions of the Korean Peninsula is the focus of research on the Early Iron Age, then ironware would be excluded as an important element of material culture. The geographic range of a study is therefore determined by the particular form of material culture being examined and its possible function and meaning to the people who used it. It could be appropriate to focus on the southern regions of the Korean Peninsula in considering developments in the Bronze Age, but in that case, one would need to recognize some inherent limitations such as the fact that metalware is hardly dealt with in the Bronze Age.

\section{Is it Archaeology? or History?}

The Early Iron Age is concurrent with the transition from the Prehistoric Age to the Historic Age. Since there were no written records of what different groups of people in Korea were called or how they identified themselves as cohesive groups before the Bronze Age, their existence can be only archaeologically assumed from the material evidence. However, Chinese literature records specific groups of people whose origins can be traced to the Early Iron Age. It is necessary to connect these written narratives about origins to archaeological knowledge.

For example, a chronology for the Early Iron Age has been established based on literary records that document the invasion of Gojoseon by Yan dynasty general Kai Qin. How to interpret historical records written by foreign invaders is an important matter, however. According to myth, Gojoseon was founded in 2333 B.C., but it would be difficult to prove that such a complex society existed during the New Stone Age on the Korean Peninsula. Archaeologists suggest that Gojoseon was established later, around 800 or 700 B.C., by which time artifacts such as lute-shaped bronze daggers and Misong-ri type pottery were being made (KAS 2010:148).

The issue then becomes where to fit Gojoseon into an archaeological chronology. Until the early 2000s, archaeological periods were divided into the Bronze Age, Early Iron Age, Proto-Three Kingdom period, and so on. Some scholars then attempted to grant historicity to the Early Iron Age by including Gojoseon in the archaeological periodic divisions assigned to the Korean Peninsula (Choi 2008; Lee 2007). Archaeologists now wonder if it is possible to actually recognize Gojoseon from an archaeological perspective and, if it is possible, what the chronology of the site would be. Even if Gojoseon is archaeologically recognized as some type of early complex society, there is also the problem of whether it is appropriate to use a name for a particular polity that existed only in the northern Korean Peninsula to represent the entire Korean Peninsula during this period.

This problem is not restricted to archaeology. Archaeologists have yet to name a specific era as "Gojoseon," but laymen often think otherwise. For instance, when Gojoseon was not included in an archaeological table established by the National Museum of Korea in 2008, some members of the public criticized it for distorting Korean history. In response, the National Museum of Korea eliminated the distinction between the Early Iron Age and the Proto-Three Kingdoms period in the archaeological table in 2009 and placed the ironware culture after the bronzeware culture. It further revised the table by including "Gojoseon," "Appearance of Many Countries," 
and "The Period of the Three States," in that order, and changed the order of the exhibition halls to: "Bronzeware \& Gojoseon Hall," "Buyeo \& The Three Han States Hall," and "The Period of the Three States Hall." The same periods are distinguished in Korean history textbooks, which aim to help the public better understand Korean history (Choi 2013: 13).

\section{CONCLUSION}

While today there are relatively few disputes about the Prehistoric Age, there continues to be much contention about the Early Iron Age, in part because it demonstrates the characteristics of a transitional period between the Prehistoric Age and the Historic Age. The Early Iron Age on the Korean Peninsula is defined as the 200 years from 300 to 100 B.C. Jeomtodae pottery, advanced bronzeware, and some ironware are typically seen as its representative material cultures. The Early Iron Age is followed by the Proto-Three Kingdoms Period (100 B.C.-A.D. 300) instead of a Late Iron Age, so the term "Early Iron Age" is neither a classical archaeological division nor an independent nomenclature for a cultural period unique to the Korean Peninsula. The term is so ambiguous that it is often replaced by "Iron Age," "Three Han States," or "Gojoseon."

The material culture of the Early Iron Age is believed by a significant number of scholars to have been introduced through collective migration from Liaoning in northeastern China to the mid-western regions of the Korean Peninsula. However, there was a time lag in the transfer of material culture to Korea. Although some archaeologists have recently suggested that Jeomtodae pottery was introduced to the Korean Peninsula around 500 B.C., most believe that Jeomtodae pottery and bronzeware were not distributed there until the fourth and third centuries B.C. Ironware was introduced in the second century B.C. and originated from the southern regions of the Korean Peninsula.

If specific elements of material culture defining the Early Iron Age were distributed through some form of large-scale migration, the societies with these different material cultures would presumably have come into contact with one another. Conflict would also have resulted in diffusion of material culture forms and technologies into the Korean Peninsula in the Bronze Age. However, there is little evidence to confirm cultural contact except for the Jeomtodae pottery excavated at Songguk-ri dwelling sites, which represents a culture of the Middle Bronze Age. However, the material culture originating from the large and complex Songguk-ri dwelling sites disappeared suddenly and a settlement system emphasizing small settlements emerged. Because there has been limited archaeological work on these settlements, it is difficult to determine whether the level of social integration was simpler or more advanced in the Early Iron Age than during the Bronze Age. For this reason, some have viewed the process of contact between the Jeomtodae pottery culture and the indigenous culture as representing a pattern of conflict, reorganization, and disintegration of the indigenous culture (Nakamura 2008).

Since the Early Iron Age is a transitional period from the Prehistoric Age to the Historic Age, it is possible to take either an archaeological perspective or historical perspective on it. Although many Koreans tend to think of archaeology as belonging to history, every researcher must decide whether to privilege material culture and deal with the Early Iron Age from a purely archaeological perspective or whether 
to give considerable weight to historical records and connect the Early Iron Age to societies such as the Gojoseon. Many hypotheses have been suggested regarding the cultural characteristics of the Early Iron Age. As increasing numbers of Jeomtodae pottery sites are discovered in the mid-western regions of the Korean Peninsula, they will contribute to a detailed understanding of cultural aspects of the Early Iron Age.

\section{REFERENCES CITED}

Choi, Sung Rak

1998 Periodization, in Theory and Practice of Korean Archaeology. Seoul: Hakyeon (in Korean).

2004 Refutation of "A Reappraisal of the Age System for the Period from 3rd Century B.C. to the 3rd Century A.D. in Korea Archaeology." Journal of the Korean Archaeological Society 54:105-118 (in Korean).

2008 Reappraisal of the chronological framework for prehistory and protohistory in Korean archaeology. Journal of the Korean Archaeological Society 67:72-93 (in Korean).

2013 Current research and prospects on the study of Early Iron Age and Proto-Three Kingdoms period in Honam Region. Journal of the Honam Archaeological Society 45:5-42 (in Korean).

Gwangju National Museum (GNM)

1988 Hampyung Chopori Site. Gwangju: GNM (in Korean).

HAN, SANG-IN

1981 Study of Jeomtodae Pottery Culture. Master's thesis. Seoul National University, Seoul (in Korean).

HCPRC (Honam Cultural Property Research Center)

2005 Wanju Galdong site I. Gwangju: HCPRC (in Korean).

2009 Wanju Galdong site II. Gwangju: HCPRC (in Korean).

JCPI (Jungwon Cultural Properties Institute)

2007 Anseong Banjeri Site. Cheongju: JCPI (in Korean).

Jo, JiN SEON

2004 A Study of Bronze Slender Daggers Culture Development Process. Ph.D. diss. Chonbuk National University, Jeonju (in Korean).

KaS (Korean Archaeological Society)

2010 A Lecture on Korean Archaeology, new ed. Seoul: Sahoepyungron (in Korean).

KiAE (Korean Institute for Archaeology \& Environment)

2001 Gwanchangri site. Seoul: KIAE (in Korean).

Kim, BumCHEOL

2001 A study of Late Mumun societies in Southern Korea. Journal of Seoul Studies 16:1-44 (in Korean).

KIM, WON-YONG

1966 Introduction to Korean Archaeology. Unpub. manuscript (in Korean).

1973 Introduction to Korean Archaeology, 1st ed. Seoul: Iljisa (in Korean).

1977 Introduction to Korean Archaeology, 2nd ed. Seoul: Iljisa (in Korean).

1986 Introduction to Korean Archaeology, 3rd ed. Seoul: Iljisa (in Korean).

KIM, YONG-GAN

1984 A Study of Namgyeong Site. Pyongyang: Publisher of Science and Encyclopedia (in Korean).

LeE, Chung-Kyu

2007 Discussion on the Proto Three Kingdoms period in Protohistory of Korea. The Journal of Korean Ancient History 46:73-100 (in Korean).

2013 Discussions about the Early Iron Age culture in South Korea. The Journal of History 46:1-26 (in Korean).

LeE, HeE-JoON

2004 A reappraisal of the Age system for the period from the 3rd century B.C. to the 3rd century A.D. in Korean archaeology. Journal of the Korean Archaeological Society 52:69-94 (in Korean).

LeE, Hyung-Won

2011 The chronology and spatial characteristics of the Clay-stripe Pottery culture originating from central South Korea. Journal of the Hoseo Archaeological Society 24:58-93 (in Korean). 
LEE, NAM-KYU

2002 Aspects of Early Iron culture that flowed into the Korean Peninsula. Journal of the Korean Ancient Historical Society 36:31-51 (in Korean).

Lim, Sul-Hee

2009 Study on the Clay-Stripe Pottery of Korea: Typology and Temporal Changes. Master's thesis. Chonnam National University, Gwangju (in Korean).

Nakamura, Daisuke

2008 Chronological research on the Korean Bronze and Early Iron Ages. Journal of the Korean Archaeological Society. 68:38-87 (in Korean).

National Museum of Korea (NMK)

1977 Namsong-ri Stonecoffin Tomb. Seoul: NMK (in Korean).

PARK, JIN-IL

2013 A Study of the Jeomtodae Ware Culture of the Korean Peninsula. Ph.D. diss. Busan National University, Busan (in Korean).

PARK, SOON-BAL

1993a History of the Han River. Seoul: Minumsa (in Korean).

1993 A A study of the development of Early Iron culture in Korea. Gogomisulsaron 3 (in Korean).

2003 The settlement process of Jeomtodae Ware culture, in The Korean Association of University Museums 49th Autumn Conference, Seoul: 57-75 (in Korean).

2004 The settlement process of the Liaoning Jeomtodae Ware culture in Korea. Gumgangogo $1: 37-64$ (in Korean).

SHIN, KYUNG-CHEOL

1995 Dongrae in Samhan period, in Donraeguji: 182-202. Busan: Dongraegu (in Korean).

SiCP (Samgang Institute of Cultural Properties)

2006 Nukdo Shell Mound II. Jinju: SICP (in Korean).

SONG, MAN-YOUNG

2013 Jeomtodae-ware settlement in central Korea and characteristics of the society, in Settlement Studies in Korea and Japan: 225-235. Seoul: Seogyungmunhwasa (in Korean).

Yi, Kun-MoO

1994 Features of Korean Type Bronze Dagger culture and the background of its appearance, in Bronze Culture in East Asia: 155-182. Seoul: National Research Institute of Cultural Heritage (in Korean).

\section{ABSTRACT}

In the prehistoric period in Korea, the appearance of metallurgy is viewed by archaeologists as having a significant impact on the growth of complex societies by providing the technology for greater agricultural production. Within Korean archaeology, the period of 300 to 100 B.C. is classified as the Early Iron Age. The Early Iron Age is situated between the Bronze Age and the Proto-Three Kingdoms period and is culturally significant because it served as a transitional period from the Prehistoric Age to the Historic Age. Despite this significance, the period's cultural characteristics, area of origin, and relationship with indigenous culture have yet to be explained. The Early Iron Age is primarily defined by the Jeomtodae (clay-striped) pottery culture and slender bronze dagger culture. Although it is generally accepted that ironware culture originated in the Early Iron Age, the Jeomtodae pottery culture and slender bronze dagger culture are not interpreted in the same way all the time. In addition, Chinese literature indicates the names of countries that existed in some parts of the Korean Peninsula. This article aims to examine the concept and cultural characteristics of the Early Iron Age and to review various issues dealt with in studies on the Early Iron Age. KeYwords: Korea, Early Iron Age, chronology, ironware, metallurgy, cultural contact, history vs. prehistory. 